\title{
Students' Trust in Research-Based Results about Potential Health Risks Presented in Popular Media
}

\begin{abstract}
Students read texts about research on consumption of artificial sweeteners and use of cell phones, respectively, that either concluded that there were serious health risks or no risks associated with consumption/use and then rated their trust in the conclusions. Results showed interactions between prior beliefs about the issues and text condition (risk vs. no risk) on trust in conclusions that were consistent with a confirmation bias assumption. Belief-biased information processing was contextualized in the sense that it varied somewhat across the two issues, however, being more pronounced for the cell phone than for the artificial sweetener issue. Additionally, some evidence was found for a distinct negativity bias in that students overall tended to trust conclusions ascertaining that there were risks more than conclusions ascertaining that there were no risks. Finally, students' self-reported use of critical reading strategies implied less trust in both types of conclusions.
\end{abstract}

Keywords: Prior beliefs, risk, trust in research, reading, undergraduates 


\section{Introduction}

Human beings seem essentially conservative, in the sense that we are reluctant to trust information that is contrary to our beliefs about how things are. In many situations this is probably a reasonable attitude; if we were ready to change our beliefs whenever we encounter new belief-inconsistent information, interpretation and understanding of our surroundings would be time consuming and require a lot of cognitive effort. Maintaining pre-existing beliefs may simply be more adaptive and pragmatic in the majority of situations (Lord \& Taylor, 2009).

Trust in new information is, however, often a precondition for learning, also when that information contradicts what we already believe to be true. Yet, people's tendency to rely on the beliefs they hold, and not trusting new information inconsistent with those beliefs, has been demonstrated within a number of areas, such as science education in elementary as well as higher education (e.g. Chinn \& Brewer, 1993; Halloun \& Hestenes, 1985; Mihelich, Sarathchandra, Hormel, Craig, \& Storrs, 2915; Renken \& Nunez, 2010), socio-scientific topics, such as climate change and AIDS (Kahan et al., 2012; Kardash \& Scholes, 1996), and social issues, such as capital punishment and school integration (Lord, Ross, \& Lepper, 1979; Murphy \& Alexander, 2004). Lack of trust in belief-inconsistent information may be problematic in educational contexts and even more so in situations where important information concerning health or personal security is presented, as in the case of many people's resistance to effective vaccination programs (Demicheli, Rivetti, Debalini, \& Di Pietrantonj, 2012). People's trust in new information may be affected by a number of different variables related to features of the source and content of the message, as well as individual variables such as prior beliefs, prior knowledge, and the perceived relevance of the message (Andreassen \& Strømsø, 2012). In the present study we focus on how students' prior topic beliefs and the nature of a message's content, independently and interactively, may affect 
their trust in research-based information about potential health risks. In addition, we explore whether students' tendency to reflect on new information and their likelihood of critically evaluating the message may also affect their trust in potentially important information on health issues.

\section{Belief biased information processing}

People's tendency to let their prior beliefs more or less unwittingly prime or guide evaluation of new information, has been observed in a number of studies and seems to be consistent across situations, in particular when the issue in question is personally relevant to the reader and when alternative perspectives exist (Nickerson, 1998). In such situations people tend to search for information that confirms what they already believe to be true and also ignore or refute belief-inconsistent information. Koehler (1993), for example, found that scientists judged research reports that confirmed their prior beliefs to be of higher quality than reports that did not. One way of reducing the value of belief-inconsistent research reports could be more or less valid critique of the methodological approach. This was demonstrated in a study by Munro (2010) where students read brief research reports about a stereotype associated with homosexuality. Results showed that students reading belief-inconsistent research reports afterwards tended to agree that the validity of the stereotype is not a question that can be addressed using scientific methods. Likewise, Greenhoot, Semb, Colombo, and Schreiber (2004) showed that students interpreted belief-inconsistent research results to be wrong. However, students emphasizing that interpretations of results should not be biased by prior beliefs also demonstrated more acceptance of belief-inconsistent interpretations of the results. That is, students who were more able to distance themselves from their prior beliefs, were also less reluctant to accept belief-inconsistent accurate interpretations. Of note is that people's distrust in belief-inconsistent information, as demonstrated across numerous contexts (Nickerson, 1998), seems to be the most common pattern when they read about results from 
scientific studies (Greenhoot et al., 2004; Kardash \& Scholes, 1996; Koehler, 1993; Lord et al., 1979; MacCoun, 1998; Munro, 2010).

Of course, a skeptical attitude towards research results is not necessarily a negative sign. Scientists often disagree, and following a Popperian logic, scientists should actively search evidence to test whether hypotheses can be disconfirmed. It may, however, be more problematic if hypotheses and research results are dismissed solely because they are inconsistent with prior beliefs. For example, there are concerns in several countries about people's skeptical attitudes towards vaccination programs (Demicheli et al., 2012), Also, people's beliefs about the causes of global warming are not necessarily based on reports from the scientific community (Kahan et al., 2012; Rudman, McLean, \& Bunzl, 2013). In the present study we introduced students to popular media reports of research on potential health risks related to cell phone radiation and the intake of artificial sweeteners, with both topics assumed to be personally relevant to our participants. Our hypothesis was that participants' prior beliefs would affect their trust in the conclusions of the reports. Some studies suggest, however, that risk topics in and of themselves may also affect readers' trust.

\section{Risk biased information processing}

Results from three studies by Siegrist and Cvetkovich (2001) indicated that people may have more trust in scientific studies that demonstrate health risks than in studies that show no risk - a "negativity bias". This pattern of confidence was shown for both more and less reputable information sources. In two later studies, Cvetkovich, Siegrist, and colleagues also included measures of participants' initial perspectives on the risk issues they read about (Cvetkovich, Siegrist, Murray, \& Tragesser, 2002). Again, new information communicating health risks was trusted more than non-risk information. In addition, Cvetkovich et al. (2002) found that this pattern was reinforced when participants' initial perspectives were in line with the new information. The same relationship between risk perception and trust was confirmed 
in studies by Eiser, Miles, and Frewer (2002), also when participants' degree of acceptance (i.e., attitudes) was controlled for. However, several later studies indicate that it actually may be quite difficult to differentiate between a "negativity bias" and a "confirmation bias" (Poortinga \& Pidgeon, 2004; White, Pahl, Buehner, \& Haye, 2003). In two studies of participants' trust in research results on the effect of food additives, White et al. (2003) found clear interactions between prior beliefs and message valence (i.e., risk/no risk) and a main effect of only prior beliefs on participants' trust in the message. Although those results only supported the "confirmation bias" hypothesis, White et al. (2003) assumed that a "negativity bias" may play a role in people's trust in risk information concerning other topics. In a study of people's trust in the regulation of genetically modified (GM) food, Poortinga and Pidgeon (2004) mainly confirmed the results from White et al (2003), except that "negativity bias" seemed to play a role for undecided people, that is, participants who did not have strong beliefs in favor of or against the regulation of GM food, with those participants seemingly finding information about risk more informative than "no-risk" information.

Findings regarding the role of a "negativity bias" are thus somewhat mixed, but there are some indications that people in a number of situations trust risk information more than norisk information. Several explanations have been suggested for the "negativity bias". Skowronski and Carlston (1989) proposed that negative behavior is generally perceived to have a higher diagnostic value than positive behavior. For example, a trustworthy person must act trustworthy most of the time to maintain that label, whereas a person labeled dishonest may rarely lie but still be regarded as dishonest. That is, negative information is often regarded as more informative than positive information, in the sense that information about potential risks tells us what to avoid whereas no-risk information does not give any specific action-related clues (Siegrist \& Cvetkovich, 2001). 
In the present study we wanted to explore whether a negativity bias might affect students' trust in risk/no-risk information when trust was also potentially predicted by participants' prior beliefs about the topic (i.e., by a confirmation bias). People's judgment of risk information may, however, also depend on how much effort they invest in evaluating different features of the message, for example whether it is reasonable and coherent, or the source of the message (Lewandowsky, Ecker, Seifert, Schwarz, \& Cook, 2012).

\section{Processing the message}

If a message is perceived by the reader as personally relevant, it is likely to elicit more processing. Still, a number of motives may bias that processing, with such motives likely to be anchored in the reader's values, identity, experience, and so forth (Lord \& Taylor, 2009; Petty \& Briñol, 2012). That is, although readers may think deeply about new information that is belief-inconsistent, they are most likely to hold on to their beliefs. Indeed, observations of people engaged in deep processing of belief-inconsistent information, show that they often intentionally put more effort into refutation of that information than into modifying their initial beliefs (Klaczynski, Gordon, \& Fauth, 1997; Lord \& Taylor, 2009; Molden \& Higgins, 2005). One way of facilitating more balanced and integrated comprehension of beliefinconsistent information, has been to instruct people to make accurate judgments and prepare to discuss the reasons for their evaluations (Lewandowsky et al., 2012; Molden \& Higgins, 2005). Other approaches to modify biased evaluation of research studies, has been to instruct participants to evaluate the studies they read from a perspective that differs from their own (Beatty \& Thompson, 2012) or to imagine that research results were the opposite of the reported results (Lord, Lepper, \& Preston, 1984). In a recent study, McCrudden and Sparks (2014) found that instructing students to carefully consider their own beliefs in light of the evidence encountered in a text might lead them to take opposing ideas more into consideration. Also, Stanovich et al. (2013) showed how explicitly instructing readers to 
decouple from prior beliefs while working on a reasoning task, facilitated less biased processing of belief-inconsistent information. Those studies suggest that people may need to become consciously aware of their prior beliefs and to make a concerted effort to evaluate new information according to other criteria or perspectives, in addition to the beliefs they hold. People do not seem to easily depart from prior beliefs and experiences, however, as they often choose to trust the first idea that comes to mind when confronted with a problem solving task (Bilalic, McLeod, \& Gobet, 2008; Frederick, 2005). Instruction in metacognitive strategies aimed at increased awareness of own beliefs and monitoring of inconsistencies while reading contradicting documents, has been demonstrated to improve students' comprehension and representation of belief-inconsistent information (Maier \& Richter, 2014). Thus, becoming aware of the prior beliefs one holds may be a precondition for the decoupling strategy suggested by Stanovich et al. (2013), while monitoring of inconsistencies could increase students' tendency to consider multiple perspectives and thereby modify people's belief biased evaluation of new information (Beatty \& Thompson, 2012).

In the current study, we included a reflection task to measure to what extent participants tended to reflect on the first solution that came to mind (Frederick, 2005) and a self-report measure targeting their likelihood of critically evaluating science-related information. Our hypotheses were that reflection and monitoring as indicated by participants' scores on those measures would be related to their degree of trust in belief-inconsistent or belief-consistent research results presented in the documents they read.

\section{The present study}

Given this theoretical background analysis, we set out to study whether students' prior beliefs about two issues involving potential health risks - cell phone radiation and the intake of artificial sweeteners - would affect their evaluation of research results presented in popular media. As both topics were presumably relevant to the participants, we expected them to 
regard research results in accordance with their prior beliefs as most trustworthy. In order to ensure that the topics were actually relevant to participants, we asked them to report how frequently they used a cell phone and consumed artificial sweeteners, respectively. Moreover, as some studies have shown that research results demonstrating risk may be regarded as more trustworthy than results demonstrating no risk, we had participants reading research reports concluding with either risk or no risk. Given mixed results from prior studies regarding a negativity bias in information processing, we had no specific hypothesis about the role of risk in their trustworthiness judgments, however. Finally, we included indicators of students' tendency to reflect on their own ideas and their evaluation of research-based claims presented in popular media. Based on prior research on students' processing of belief-inconsistent information (e.g. Maier \& Richter, 2014; McCrudden and Sparks, 2014), we expected that higher degrees of cognitive reflection and reportedly more use of critical evaluation strategies when encountering science-related information would be associated with more cautious evaluation of the trustworthiness of presented claims.

\section{Method}

\section{Participants}

The sample consisted of 170 (55.9\% females) first-year students at a university college in south-east Norway. Participants were selected from a total sample of 262 students, with only students demonstrating accurate recall of conclusions from the two texts they read in the study included in the analyses. They had an overall mean age of $23.5(S D=6.2)$ and attended three different bachelor-level programs: teaching $(n=70)$, engineering $(n=42)$, and economics $(n=58)$. Participation in the project was voluntary and all data were treated anonymously and confidentially.

\section{Materials}


Texts. Each participant read one 325-word text on the controversial issue of whether the artificial sweetener aspartame might pose any health risk and one 379-word text on the controversial issue of whether cell phone radiation might have any negative health effects. The artificial sweetener (aspartame) text was from a bi-weekly magazine for the health care sector called Today's Medicine; the cell phone text from a popular science magazine called Illustrated Science.

The two texts were presented on separate sheets of paper. The text on artificial sweeteners was written by the named editor of the health care magazine, and in addition to this information about the author and the author's credentials, information about the publication and the date of creation was provided. The text on cell phone use was written by a named research reporter, with information about the publication and date of publication also provided.

Both texts consisted of four paragraphs, including the same type of content across texts. In the first paragraph, the issue was briefly introduced and readers were told that some people think that intake of artificial sweeteners/use of cell phones may cause serious health problems, whereas others think that both are perfectly safe. The second paragraph explained in neutral terms how artificial sweeteners are produced and digested and how cell phones work, respectively. In the third paragraph, it was referred to a recent research review by an expert on the issue in question, providing information about the different types of investigations that were included in the reviews. Finally, we manipulated the emphasis on risk by varying the conclusion in the fourth paragraph of each text. Thus, in the high risk versions, the conclusion stated that, based on the expert review, existing research provides scientific evidence that there is a relationship between the intake of artificial sweeteners/cell phone use and health problems. In the low-risk versions, the conclusion stated that scientific evidence 
disproves that such a relationship exists. Please note that the only difference between the risk and no-risk version of a text was the opposite conclusion.

The two texts contained passages collected from authentic sources that participants would typically encounter when reading to inform themselves about the issues in question, while the conclusions were created by the authors of this study

Self-reported intake of artificial sweeteners and use of cell phones. Participants were asked to mark on a scale from 1 to 5 their intake of drinks containing artificial sweeteners during a week, and how many minutes during an ordinary day they spent talking on their cell phone. For the artificial sweeteners item, response alternatives were 1: 0-0.5 liter, 2: 0.5-2 liters, 3: 2-4 liters, 4: 4-6 liters, and 5: more than 6 liters. The response alternatives for the cell phone item were 1: 1-5 min., 2: 5-20 min., 3: 20-60 min., 4: 60-120 min., and 5: more than $120 \mathrm{~min}$.

Topic beliefs. Participants' prior topic beliefs were assessed with a four-item inventory using a 10 -point scale $(1=$ not at all true, $10=$ very true $)$ that asked participants to rate their agreement with two statements concerning artificial sweeteners ("I believe there is a relationship between intake of the artificial sweetener aspartame and health problems" and "I do not believe that intake of artificial sweeteners can impair one's health" [reverse coded]), with scores yielding a Cronbach's $\alpha$ of .82, and two items concerning cell phones ("I believe that cell phone use can impair one's health" and "I do not believe that cell phone radiation can cause cancer" [reverse coded]), with scores yielding a Cronbach's $\alpha$ of .92 .

Self-reported prior knowledge. As a proxy for prior knowledge, we used three items to assess participants' perceived knowledge of or familiarity with each of the issues discussed in the texts. For the issue of artificial sweeteners, participants rated their knowledge about (1) different types of artificial sweeteners and what they contain, (2) possible health problems when using artificial sweeteners in food and drink, and (3) how researchers investigate 
whether use of artificial sweeteners might involve any health risk (Cronbach's $\alpha=.88$ ).

Regarding the issue of cell phones, participants rated their knowledge about (1) how cell phones send and receive signals, (2) possible health problems when using cell phones, and (3) how researchers investigate whether cell phone use might involve any health risk (Cronbach's $\alpha=.73$ ). On all items, participants rated their agreement with the knowledge statements ("I have knowledge about ...") on a 10-point scale $(1=$ disagree completely, $10=$ agree completely). Prior research has found perceived knowledge to be quite a good indicator of students' scores on knowledge measures (Stanovich \& West, 2008) and to play an important role in their judgments of new information (Andiliou, Ramsay, Murphy, \& Fast, 2012).

Cognitive reflection test. The Cognitive Reflection Test (CRT) (Frederick, 2005) was used to assess participants' general ability to suppress an intuitive and spontaneous wrong answer in favor of a reflective correct answer. The test is composed of three tasks (sample item: "A bat and a ball cost $\$ 1.10$ in total. The bat costs a dollar more than the ball. How much does the ball cost?") and right answers were scored with 1 point for each of the three tasks (maximum score $=3$ ). The internal consistency reliability (Cronbach's $\alpha$ ) for scores on the three-item measure was .57 , with this somewhat low level of reliability probably attributable to the fact that particular items were very hard for our participants.

The CRT has also been described as a measure of one's "tendency to accept heuristically triggered responses" (Toplak, West, \& Stanovich, 2011, p.1284). In several studies, it has been shown to correlate moderately with both cognitive ability and skills in rational thinking, but also to independently predict central aspects of rational thought (Frederick, 2005; Toplak et al., 2011).

Trust in conclusion. After having read the texts, participants were asked to write down the main conclusion of each ("What was the main conclusion of this text?"). In order to avoid memory biases, only students recalling the conclusion accurately were included in the 
analyses reported in this article. They were then asked to rate the extent to which they trusted the conclusion (“To what degree do you trust this conclusion?"), using a 5-point scale ranging from not at all (1) to to a very high degree (5).

Critical reading of media reports of science. To assess participants' likelihood of critically evaluating science-related information presented in popular media, we developed the Critical Reading of Media Reports of Science Scale (CROMROSS). Three of the items were adapted from the Critical Thinking subscale of the Motivated Strategies for Learning Questionnaire (MSLQ) (Pintrich, Smith, Garcia, \& McKeachie, 1993), which was designed to measure students' use of strategies to make critical evaluations of ideas by applying previous knowledge to new situations. On the CROMROSS, however, readers were asked to rate their agreement with statements concerning how they relate to information about research and science presented in popular media such as newspapers, magazines, radio, television, or various websites, with all six items included in the scale addressing to what extent readers judge the plausibility of claims through critical thinking (sample items: "When I see claims about new knowledge and new discoveries in the media, I consider how well justified these claims are" and "When media present a theory, interpretation, or conclusion about a scientific issue, I try to judge whether there are other possible explanations"). All six items were rated on a 5 -point scale $(1=$ very seldom, $5=$ very often $)$. The reliability estimate (Cronbach's $\alpha)$ for participants' scores on this measure was 87 .

\section{Procedure}

Materials were group administered to the participants in each of the three bachelor programs separately during regular 45 -min lectures. The data collection was administrated by the first and second authors together with four trained research assistants.

Each participant received a folder containing all the materials. They answered a questionnaire on demographics before responding to the self-reported intake of artificial 
sweeteners and use of cell phone scales, the four topic belief items, and the six perceived knowledge items. The two texts were then introduced with the following instruction, written on a separate sheet of paper: "We have copied two articles on current health issues. Read these articles carefully to decide whether you ought to change some of your own habits. When you have finished, you will get some questions about what you read. It is therefore important that you try to remember what you read in these articles." The texts were then presented on separate sheets of paper in counterbalanced order. Participants did not look back to the texts while completing the remaining tasks. Students read texts on both topics in either the risk (98 students) or no-risk (72 students) condition.

After finishing the texts, participants first worked on the Cognitive Reflection Test (CRT), and were afterwards asked to state the main conclusion of the text they had read first and to rate the extent to which they trusted the recalled conclusion. Participants then completed the same tasks in the same order for the other text.

Finally, participants completed the Critical Reading of Media Reports of Science Scale (CROMROSS). This scale was administered last because we intended that participants should process the texts without being cued on the importance of critically evaluating their claims. All participants finished the tasks within the allotted 45 minutes.

Only the 170 students that recalled the conclusions correctly were included in subsequent statistical analyses, with that procedure followed to control for potential memory biases.

\section{Results}

Preliminary analyses using independent samples $t$-tests showed no statistically significant differences between participants in the no-risk and risk conditions with respect to prior topic beliefs $(M=6.62, S D=2.46$ vs. $M=6.89, S D=2.39, t[166]=-.71, p=.48$, Cohen's $d=.11$, for artificial sweeteners; $M=6.08, S D=2.61$ vs. $M=5.75, S D=2.68, t[168]$ 
$=.79, p=.43$, Cohen's $d=.12$, for cell phone use), self-reported topic knowledge $(M=3.77$, $S D=2.02$ vs. $M=4.05, S D=2.25, t[167]=-.81, p=.42$, Cohen's $d=.13$, for artificial sweeteners; $M=4.07, S D=1.99$ vs. $M=4.37, S D=1.88, t[167]=-1.03, p=.31$, Cohen's $d$ $=.15$, for cell phone use), self-reported intake of artificial sweeteners $(M=1.96, S D=1.08$ vs. $M=1.92, S D=1.03, t(168)=.25, p=.81$, Cohen's $d=.04)$, or self-reported use of cell phones $(M=1.83, S D=.84$ vs. $M=1.82, S D=.83, t(168)=.13, p=.90$, Cohen's $d=.01)$.

We also ran two paired samples $t$-test to see if participants' initial beliefs and selfreported knowledge differed between the two topics. Results showed that participants tended to have stronger beliefs about the intake of artificial sweeteners $(M=6.75, S D=2.41)$ than about the use of cell phones $(M=5.85, S D=2.64)$ as a potential health risk, with $t(167)=$ $3.78, p<.001$, Cohen's $d=.36$. Participants also reported statistically significantly lower knowledge about artificial sweeteners $(M=3.93, S D=2.15)$ than about cell phones $(M=4.24$, $S D=1.93)$, with $t(168)=-1.99, p<.05$, Cohen's $d=.15$.

[Table 1 about here]

Table 1 presents descriptive data and correlations between variables for the artificial sweetener topic. Gender (females = -1 , males = 1) correlated positively with participants' selfreported intake of artificial sweeteners $(r=.25, p<.01)$, indicating that males were more likely to report a higher weekly intake than females. Males were also likely to outperform females on the CRT $(r=.16, p<.05)$ and report higher scores on the CROMROSS $(r=.20, p$ $<.05)$. Moreover, there was a statistically significant negative correlation between selfreported intake of artificial sweeteners and prior topic beliefs $(r=-.17, p<.05)$, indicating that the more artificial sweeteners participants consumed the less they believed in a relationship between such consumption and potential health risks. Prior topic beliefs correlated positively with self-reported knowledge $(r=.19, p<.05)$, indicating that the more participants believed in potential health risks related to the intake of artificial sweeteners, the 
more they reportedly knew about the topic. There was also a clear relationship between scores on the CRT and the CROMROSS $(r=.40, p<.001)$, indicating that participants' tendency to suppress intuitive and spontaneous answers was positively related to their self-reported critical reading skills. Finally, CROMROSS was negatively correlated with participants' trust in the conclusion $(r=-.20, p<.05)$, with higher scores on the critical reading measure associated with lower trust in the text's conclusion.

[Table 2 about here]

Table 2 presents descriptive data and correlations between variables for the cell phone topic. Gender was positively related to participants' self-reported knowledge about the topic $(r=.18, p<.05)$, indicating that males were more likely to report a higher level of knowledge than females. Self-reported knowledge was also positively related to scores on the CROMROSS $(r=.16, p<.05)$, whereas CROMROSS scores correlated negatively with students trust in text's conclusion $(r=-.30, p<.001)$.

Next we ran two hierarchical multiple regression analyses with trust in the artificial sweetener and the cell phone conclusions, respectively, as dependent measures. In both analyses, gender, self-reported intake of artificial sweeteners/use of cell phones, and selfreported topic knowledge were entered into the equation in Step 1. In Step 2, we included scores on the CRT, the CROMROSS, text condition, and scores on the topic belief measure, as well as a variable representing the cross-product multiplicative term between topic beliefs and text condition. Gender (females $=-1$, males $=1)$ and text condition $($ no risk $=-1$, risk $=1$ ) were contrast-coded before the two regression analyses were performed. To prevent multicollinearity among the first-order terms and the interaction term, the interaction term was created and regression analysis performed after centering the topic belief variable (Aiken $\&$ West, 1991). Table 3 shows the results of the first hierarchical regression analysis with trust in the artificial sweetener conclusion as the dependent variable. 
[Table 3 about here]

In Step 1, gender, self-reported intake of artificial sweeteners, and self-reported knowledge did not explain a statistically significant amount of the variance in the trust score, $R^{2}=.01, F(3,155)=.41, n s$. However, the variables entered in Step 2 accounted for a statistically significant increment in the explained variance of trust in the conclusion, $R^{2}=.29$, $F_{\text {change }}(5,150)=11.89, p<.001$. In this step, a statistically significant negative relationship was found for CROMROSS, $\beta=-.16, p<.05$, indicating that students' self-reported use of critical reading strategies were negatively related to their trust in the conclusion of the artificial sweetener text. There was a statistically significant positive relationship between text condition and trust in the conclusion, $\beta=.43, p<.001$, with students that read the text concluding that intake of artificial sweeteners is related to health risks being more likely to trust the text's conclusion than students reading the text disproving the existence of such a relationship. Finally, the interaction term between topic beliefs and text condition uniquely predicted trust in the conclusion, with $\beta=.20, p<.01$. Following Aiken and West (1991), we graphed the statistically significant interaction to interpret its nature. Figure 1 indicates that the relation between topic beliefs and trust in the conclusion depended on the text version that participants had been reading. Specifically, when participants read that there was a risk, they tended to put more trust in the conclusion the stronger their prior beliefs in a causal relationship between the intake of artificial sweeteners and health problems, and when participants read that there was no risk, they tended to put less trust in the conclusion the stronger their prior beliefs in such a causal relationship. In particular, participants that initially believed strongly in potential health risks seemed to trust a text conclusion confirming those beliefs more than a conclusion disconfirming them.

[Figure 1 about here] 
Table 4 shows the results of the second hierarchical regression analysis with trust in the cell phone conclusion as the dependent variable. Again, the three variables entered in Step 1 did not explain a statistically significant amount of the variance in the trust score, $R^{2}$ $=.03, F(3,156)=2.48, n s$. There was, however, a statistically significant negative relationship between gender and trust, $\beta=-.17, p<.05$, indicating that females tended to trust the conclusion more than males. The variables entered in Step 2 accounted for a statistically significant increment in the explained variance of trust in the conclusion, $R^{2}=.38, F_{\text {change }}(5$, $151)=19.80, p<.001$. Students' self-reported cell phone use had a statistically

[Table 4 about here] significant negative relationship with trust in the conclusion, $\beta=-.16, p<.05$, indicating that the more participants reportedly used cell phones, the less likely they were to trust the conclusion. Again the CROMROSS score predicted trust in the conclusion negatively, $\beta=$ $.19, p<.01$ : the higher scores participants had on the critical reading strategy measure, the less they seemed to trust the conclusion stated in the text that they read. As for the artificial sweetener text, the text condition was positively related to the trust score, $\beta=.19, p<.01$, indicating that participants in the risk condition trusted the conclusion more than those in the no-risk condition. Finally, the interaction term between topic beliefs and text condition uniquely predicted trust in the conclusion, with $\beta=.54, p<.001$. The graphed interaction displayed in Figure 2 indicates that the relation between topic beliefs and trust in the conclusion depended on the text version that participants had been reading. Thus, when participants read that there was a risk, they tended to put more trust in the conclusion the stronger their prior beliefs in a causal relationship between cell phone use and health problems, and when participants read that there was no risk, they tended to put less trust in the conclusion the stronger their prior beliefs in such a causal relationship. Participants that initially believed strongly in potential health risks seemed to trust a text conclusion 
confirming those beliefs much more than a conclusion disconfirming them, and participants that initially rejected the idea of a causal relationship between cell phone use and health problems seemed to trust a conclusion confirming those beliefs much more that an opposite conclusion.

\section{[Figure 2 about here]}

\section{Discussion}

The present study contributes to the literature on students' reading of scientific results on risk topics in popular media by presenting new findings regarding belief- and risk-biased evaluations. In addition, our study provides new data on the potential relationships between cognitive reflection and reports of critical reading strategies on the one hand, and student evaluations of research-based conclusions on the other.

Based on previous studies of belief-biased information processing of research results (e.g., Greenhoot et al., 2004; Koehler, 1993; Munro, 2010), we expected that participants would consider conclusions in accordance with their prior topic beliefs to be most trustworthy. Our results were consistent with that expectation, with the interaction effect observed for both topics demonstrating that participants, in general, were much more likely to trust conclusions confirming their pre-existing beliefs about the issues than conclusions contradicting those beliefs. This corroborates prior work by White et al. (2003), who observed an interaction between prior beliefs and risk condition on people's trust in information about food additives. Of note is that the observed confirmation bias seemed even more salient for the cell phone than for the artificial sweetener topic, indicating that belief-biased evaluation of risk information may vary across topics, with such variation across topics also assumed (but not demonstrated) by White et al. (2003). Presumably, the participants in this study had been more frequently exposed to popular media information on possible health risks of cell phone use than of artificial sweeteners. For example, respective Google searches with the term 
"health risks" connected to each of the two topics resulted in 3.2 times as many hits for the cell phone topic as for the artificial sweetener topic. It is thus conceivable that a higher awareness of different public opinions regarding potential risks of using cell phones might underlie a stronger confirmation bias for that topic, as participants probably were more aware of the stances taken by public opinion-formers on the issue. Thus, students' beliefs regarding the cell phone topic may well be more strongly anchored in values and identity (Lord \& Taylor, 2009; Petty \& Briñol, 2012) and thereby affect trust to a greater degree than for the artificial sweetener topic, even though they initially had stronger beliefs about the artificial sweetener than the cell phone topic. This hypothesis should, however, be studied empirically in future work.

Although several prior studies have indicated that people seem to trust scientific studies demonstrating health risks more than studies demonstrating no health risks (e.g., Cvetkovich et al., 2002; Eiser et al., 2002; Siegrist \& Cvetkovich; 2001), other studies suggest that it may be difficult to differentiate between biases related to risk information and biases based on prior topic beliefs (Poortinga \& Pidgeon, 2004; White et al., 2003). Given such mixed results, we did not have a clear expectation regarding whether the text condition (i.e., risk vs. no-risk) would be associated with students' trust in the texts' conclusions. However, the results showed that the text condition uniquely predicted the trust score for both topics, with students reading conclusions highlighting health risks trusting those conclusions more than students reading that there were no risks trusted the no-risk conclusions. Our results thereby support the assumption of a distinct negativity bias set forth by Siegrist and Cvetkovich (2001), proposing that people generally find risk information more trustworthy than information refuting risk.

Finally, we expected that students' cognitive reflection and their self-reported use of critical evaluation strategies would be related to how much they trusted the texts' conclusions. 
Students' scores on the Cognitive Reflection Test did not show any statistically significant relationship with their trust in the conclusions, however. This may be explained by the low scores $(M=.29)$ on the CRT, which indicate that participants were not able to suppress intuitive and spontaneous wrong answers that immediately came to mind and reflect on alternative solutions to the extent that such skills could be brought to bear on the evaluation of research-based conclusions.

Students' self-reported critical reading of science-related information presented in popular media, as assessed with the CROMROSS, was, however, related to their trust scores for conclusions across texts. Specifically, higher scores on the critical reading self-report measure predicted lower trust in the texts' conclusions. This suggests that whether conclusions were belief consistent or belief inconsistent, students' inclination to critically evaluate science-related information was related to how much they trusted such information. Of note is that while higher CROMROSS scores might reflect a deeper processing of information, this does not necessarily imply a modification of initial beliefs (Klaczynski et al., 1997; Lord \& Taylor, 2009; Molden \& Higgins, 2005). Rather, awareness of and reflection on prior beliefs seem to be important preconditions for less biased information processing (McCrudden \& Sparks, 2014; Maier \& Richter, 2014; Stanovich et al., 2013). More critical reading as possibly reflected in higher CROMROSS scores may thus have to be coupled with higher levels of awareness of and reflection on own beliefs to really counteract biased information processing. In the current study, students' self-reported use of critical reading strategies may indicate a more skeptical attitude towards the text conclusions, yet the results do not inform on whether their beliefs about the two risk topics were modified by reading the texts.

\section{Limitations}


The sample in our study consisted of first year students from three bachelor degree programs, and one should be careful to generalize to other groups of students. Participants' self-reported prior knowledge on the topics was, however, not particular high, and in line with what could be expected from the general public. Also, participants' self-reported intake of artificial sweeteners and use of cell phones seem to fit the pattern of similar age groups in Norway (Norwegian Post and Telecommunications Authority, 2013; Stea, Øverby, Klepp, \& Bere, 2011). We do, however, not know whether participants' scores on the other predictor variables are representative for a larger population.

The internal consistency reliability of the Cognitive Reflection Test is also of some concern. Given that this measure was used for research purposes, and that the measure has been validated in a number of prior studies (e.g., Frederick, 2005; Toplak et al., 2011), we still decided to include it in our analyses as the CRT seems to be a valid measure of students' tendency to further reflect on their initial thoughts and beliefs. However, given the relatively low estimated reliability and the low student scores on this measure, alternative measures of such reflection should be considered in future studies.

In future studies one should also consider including measures of other kinds of beliefs. Recently, Sinatra, Kienhues, and Hofer (2014) suggested that research from the fields of epistemic cognition and conceptual change should complement research on the role of topic beliefs in scientific literacy, and prior studies have demonstrated that epistemic beliefs may affect both students' trust in and comprehension of research results presented in popular media (e.g. Bråten, Strøms $\varnothing$, \& Samuelstuen, 2008; Strømsø, Bråten, \& Britt, 2011).

\section{Conclusion}

Many of our everyday decisions are influenced by information we encounter in popular media on scientific results, and information related to personal health issues is quite common in this regard. How we deal with such information may be of vital importance in 
some instances, making it pertinent to identify variables that may affect such information processing. Several decades of research have indicated that people's prior topic beliefs are important when they decide what information to trust (Andreassen \& Strøms $\varnothing, 2012$ ). Less is known about the role of personal risk. The present study suggests that both topic beliefs and risk perceptions may affect people's trust in information about health issues, and that these variables may interact in determining people's judgments of trustworthiness. In trying to make informed decisions about health issues of personal relevance, people would probably profit from paying more attention to their own attitudes towards those issues as well as being aware that the nature of the message may influence their interpretation of information concerning potential health risks.

\section{References}

Aiken, L.S., \& West, S.G. (1991). Multiple regression: Testing and interpreting interactions. Newbury Park, CA: Sage.

Andiliou, A., Ramsay, C.M., Murphy, K., \& Fast, J. (2012). Weighing opposing positions: Examining the effects of intratexual persuasive messages on students' knowledge and beliefs. Contemporary Educational Psychology, 37, 113-127. doi: 10.1016/j.cedpsych.2011.10.001

Andreassen, R., \& Strøms $\varnothing$, H.I. (2012). Reading about health risks: Who and what to trust? A research review. In K.P. Knutsen, S. Kvam, P. Langemeyer, A. Parianou, \& K. Solfjeld (Eds.). Narratives of risk. Interdisciplinary studies (255-274). Münster, Germany: Waxmann.

Beatty, E.L., \& Thompson, V.A. (2012). Effects of perspective and belief on analytic reasoning in a scientific reasoning task. Thinking \& Reasoning, 18, 441-460. doi: $10.1080 / 13546783.2012 .687892$ 
Bilalic, M., McLeod, P., \& Gobet, F. (2008). Why good thoughts block better ones: The mechanism of the pernicious Einstellung (set) effect. Cognition, 108, 652-661. doi:10.1016/j.cognition.2008.05.005

Bråten, I., Strømsø, H.I., \& Samuelstuen, M.S. (2008). Are sophisticated students always better? The role of topic-specific personal epistemology in the understanding of multiple expository texts. Contemporary Educational Psychology, 33, 814-840. doi:10.1016/j.cedpsych.2008.02.001

Cvetkovich, G., Siegrist, M., Murray, R., \& Tragesser, S. (2002). New information and social trust: Asymmetry and perseverance of attributions about hazard managers. Risk Analysis, 22, 359-367. doi: 10.1111/0272-4332.00030

Chinn, C.A., \& Brewer, W.F. (1993). The role of anomalous data in knowledge acquisition: A theoretical framework and implications for science instruction. Review of Educational Research, 63, 1-49. doi: 10.3102/00346543063001001

Demicheli, V., Rivetti, A., Debalini, M.G., \& Di Pietrantonj, C. (2012). Vaccines for measles, mumps and rubella in children. Cochrane Database of Systematic Reviews, Issue 2. Art. No. CD004407. doi: 10/1002/14651858.CD004407.pub3.

Eiser, J.R., Miles, S., \& Frewer, L.J. (2002). Trust, perceived risk, and attitudes toward food technologies. Journal of Applied Social Psychology, 32, 2423-2433. Doi: 10.1111/j.1559-1816.2002.tb01871.x

Frederick, S. (2005). Cognitive reflection and decision making. Journal of Economic Perspectives, 19, 25-42. doi: 10.1257/089533005775196732

Greenhoot, A.F., Semb, G., Colombo, J., \& Schreiber, T. (2004). Prior beliefs and methodological concepts in scientific reasoning. Applied Cognitive Psychology, 18, 203-221. doi: 10.1002/acp.959

Hallouna, I.A., \& Hestenes, D. (1985). The initial knowledge state of college physics 
students. American Journal of Physics, 53, 1043-1048.

Kahan, D.M., Peters, E., Wittlin, M., Slovic, P., Ouellette, L.L., Braman, D., \& Mandel, G. (2012). The polarizing impact of science literacy and numeracy on perceived climate change risks. Nature Climate Change, 2, 732-735. doi: 10.1038/nclimate1547

Kardash, C.M., \& Scholes, R.J. (1996). Effects of preexisting beliefs, epistemological beliefs, and need for cognition on interpretation of controversial issues. Journal of Educational Psychology, 88, 260-271. doi: 10.1037/0022-0663.88.2.260

Klaczynski, P.A., Gordon, D.H., \& Fauth, J. (1997). Goal-oriented critical reasoning and individual differences in critical reasoning biases. Journal of Educational Psychology, 89, 470-485. doi: 10.1037/0022-0663.89.3.470

Koehler, J.J. (1993). The influence of prior beliefs on scientific judgments of evidence quality. Organizational Behavior and Human Decision Processes, 56, 28-55.

Lewandowsky, S., Ecker, U.K.H., Seifert, C.M., Schwarz, N., \& Cook, J. (2012).

Misinformation and its correction: Continued influence and successful debiasing. Psychological Science in the Public Interest, 13, 106-131. doi:

$0.1177 / 152910061245101018$

Lord, C.G., Lepper, M.R., \& Preston, E. (1984). Considering the opposite: A corrective strategy for social judgment. Journal of Personality and Social Psychology, 47, 12311243. doi: 10.1037/0022-3514.47.6.1231

Lord, C.G., Ross, L., \& Lepper, M.R. (1979). Biased assimilation and attitude polarization: The effects of prior theories on subsequently considered evidence. Journal of Personality and Social Psychology, 37, 2098-2109. doi: 10.1037/00223514.37.11.2098

Lord, C.G., \& Taylor, C.A. (2009). Biased assimilation: Effects of assumptions and 
expectations on the interpretation of new evidence. Social and Personality Psychology Compass, 3, 827-841. doi: 10.1111/j.1751-9004.2009.00203.x

MacCoun, R.J. (1998). Biases in the interpretation and use of research results. Annual Review of Psychology, 49, 259-287. doi: 10.1146/annurev.psych.49.1.259

Maier, J., \& Richter, T. (2014). Fostering multiple text comprehension: How metacognitive strategies and motivation moderate the text-belief consistency effect. Metacognition and Learning, 9, 51-74. doi: 10.1080/07370008.2013.769997

McCrudden, M.T., \& Sparks, P.C. (2014). Exploring the effect of task instruction on topic beliefs and topic belief justification: A mixed methods study. Contemporary Educational Psychology, 39, 1-11. doi: 10.1016/j.cedpsych.2013.10.001

Mihelich, J.A., Sarathchandra, D., Hormel, L., Craig, T., \& Storrs, D.A. (2015). The cultural negotiation of publics-science relations: Effects of Idaho residents' orientation toward science on support for K-12 STEM education. Bulletin of Science, Technology \& Society, 35, 166-177. doi: 10.1177/0270467616633554

Molden, D.C., \& Higgins, E.T. (2005). Motivated thinking. In K. J. Holyoak \& R. G. Morrison (Eds.), The Cambridge handbook of thinking and reasoning (pp. 295-320). New York: Cambridge University Press.

Munro, G.D. (2010). The scientific impotence excuse: Discounting belief-threatening scientific abstracts. Journal of Applied Social Psychology, 21, 579-600. doi: 10.1111/j.1559-1816.2010.00588.x

Murphy, P.K., \& Alexander, P.A. (2004). Persuasion as a dynamic, multidimensional process: An investigation of individual and intraindividual differences. American Educational Research Journal, 41, 337-363. doi: 10.3102/00028312041002301

Nickerson, R.S. (1998). Confirmation bias: A ubiquitous phenomenon in many guises. Review of General Psychology, 2, 175-220. doi: 10.1037/1089-2680.2.2.175 
Norwegian Post and Telecommunications Authority (2013). Befolkningens bruk av elektroniske kommunikasjonstjenester [The population's use of electronic communication]. Oslo: NPT.

Petty, R.E., \& Briñol, P. (2012). The elaboration likelihood model. In P.A.M. Van Lange, A. Kruglanski, \& E.T. Higgins (Eds.). Handbook of theories of social psychology (pp. 224-245). London: Sage.

Pintrich, P.R., Smith, D.A.F., Garcia, T., \& McKeachie, W.J. (1993). Reliability and predictive validity of the Motivated Strategies for Learning Questionnaire (MSLQ). Educational and Psychological Measurement, 53, 801-813. doi: $10.1177 / 0013164493053003024$

Poortinga, W., \& Pidgeon, N.F. (2004). Trust, the asymmetry principle, and the role of prior beliefs. Risk Analysis, 24, 1475-1486. doi: 10.1111/j.0272-4332.2004.00543.x

Renken, M.D., \& Nunez, N. (2010). Evidence for improved conclusion accuracy after reading about rather that conducting a belief-inconsistent simple physics experiment. Applied Cognitive Psychology, 24, 792-811. doi: 10.1002/acp.1587

Rudman, L.A., McLean, M.C., \& Bunzl, M. (2013). When truth is personally inconvenient, attitudes change: The impact of extreme weather on implicit support for green politicians and explicit climate-change beliefs. Psychological Science, 24, 2290-2296. doi: $10.1177 / 0956797613492775$

Siegrist, M., \& Cvetkovich, G. (2001). Better negative than positive? Evidence of a bias for negative information about possible health dangers. Risk Analysis, 21, 199-206. doi: 10.1111/0272-4332.211102

Sinatra, G.M., Kienhues, D., Hofer, B.K. (2014). Addressing challenges to public understanding of science: Epistemic cognition, motivated reasoning, and conceptual change. Educational Psychologist, 49, 123-138. doi: 10.1080/00461520.2014.916216 
Skowronski, J.J., \& Carlston, D.E. (1989). Negativity and extremity biases in impression formation: A review of explanations. Psychological Bulletin, 105, 131-142. doi: $10.1037 / 0033-2909.105 .1 .131$

Stanovich, K.E., \& West, R.F. (2008). On the relative independence of thinking biases and cognitive ability. Journal of Personality and Social Psychology, 94, 672-695. doi: $10.1037 / 0022-3514.94 .4 .672$

Stanovich, K.E., West, R.F., \& Toplak, M.E. (2013). Myside bias, rational thinking, and intelligence. Current Directions in Psychological Science, 22, 259-264. doi: $10.1177 / 0963721413480174$

Stea, T.H., Øverby, N.C., Klepp, K.I., \& Bere, E. (2011). Changes in beverage consumption in Norwegian children from 2001 to 2008. Public Health Nutrition, 15, 379-385. doi: $10.1017 / \mathrm{S} 1368980011001959$

Strømsø, H.I., Bråten, I., \& Britt, M.A. (2011). Do students' beliefs about knowledge and knowing predict their judgment of texts' trustworthiness? Educational Psychology, 31, 177-206. doi: 10.1080/01443410.2010.538039

Toplak, M.E., West, R., \& Stanovich, K.E. (2011). The Cognitive Reflection Test as a predictor of performance on heuristics and biases tasks. Memory \& Cognition, 39, 1275-1289. doi: 10.3758/s13421-011-0104-1

White, M.P., Pahl, S., Buehner, M., Haye, A. (2003). Trust in risky messages: The role of prior attitudes. Risk Analysis, 23, 717-726. doi: 10.1111/1539-6924.0035 
Table 1

Descriptive statistics and zero-order correlations between variables for the artificial sweeteners topic

\begin{tabular}{|c|c|c|c|c|c|c|c|}
\hline Variable & 1 & 2 & 3 & 4 & 5 & 6 & 7 \\
\hline 1. Gender & - & & & & & & \\
\hline 2. Self-reported intake of artificial sweeteners & $.25^{* *}$ & - & & & & & \\
\hline 3. Topic beliefs - artificial sweeteners & -.10 & $-.17 *$ & - & & & & \\
\hline 4. Self-reported knowledge - artificial sweeteners & -.13 & -.01 & $.19^{*}$ & - & & & \\
\hline 5. Cognitive reflection (CRT) & $.16^{*}$ & -.01 & .12 & .05 & - & & \\
\hline 6. Critical reading (CROMROSS) & $.20 *$ & -.07 & .02 & .13 & $.40 * * *$ & - & \\
\hline 7. Trust in conclusion - artificial sweeteners & -.11 & -.04 & .13 & .06 & -.09 & $-.20 *$ & - \\
\hline$M$ & & 1.94 & 6.78 & 3.93 & .29 & 3.12 & 3.29 \\
\hline$S D$ & & 1.05 & 2.42 & 2.15 & .33 & .87 & .94 \\
\hline Skewness & & .94 & -.50 & .79 & .80 & .29 & -.22 \\
\hline
\end{tabular}

Note. $* p<.05, * * p<.01, * * * p<.001$.

Gender: females $=-1$, males $=1$. 
Table 2

Descriptive statistics and zero-order correlations between variables for the cell phone topic

\begin{tabular}{|c|c|c|c|c|c|c|c|}
\hline Variable & 1 & 2 & 3 & 4 & 5 & 6 & 7 \\
\hline 1. Gender & - & & & & & & \\
\hline 2. Self-reported use of cell phone & -.10 & - & & & & & \\
\hline 3. Topic beliefs - Cell phone & -.14 & .06 & - & & & & \\
\hline 4. Self-reported knowledge - Cell phone & $.18^{*}$ & .13 & .11 & - & & & \\
\hline 5. Cognitive reflection (CRT) & $.16^{*}$ & -.12 & .03 & .07 & - & & \\
\hline 6. Critical reading (CROMROSS) & $.20^{*}$ & -.05 & .05 & $.16^{*}$ & $.40 * * *$ & - & \\
\hline 7. Trust in conclusion - Cell phone & -.13 & -.12 & .05 & -.08 & -.11 & $-.30 * * *$ & - \\
\hline$M$ & & 1.82 & 5.89 & 4.24 & .29 & 3.12 & 3.15 \\
\hline$S D$ & & .83 & 2.65 & 1.93 & .33 & .87 & .94 \\
\hline Skewness & & .97 & -.23 & .57 & .80 & .29 & -.21 \\
\hline
\end{tabular}

Note. $* p<.05, * * p<.01, * * * p<.001$.

Gender: females $=-1$, males $=1$. 
Table 3

Results of hierarchical analysis for variables predicting trust in the conclusion from the artificial sweetener text

Variable

$B$

$S E B$ $\beta$

Step 1

Gender $-.08$

.08

$-.09$

Self-reported intake of artificial sweeteners

.00

.07

.00

Self-reported knowledge - artificial sweeteners

.00

.04

.00

Step 2

Gender

$-.05$

.07

$-.05$

Self-reported intake of artificial sweeteners

.03

.06

.04

Self-reported knowledge - artificial sweeteners

.00

.03

.00

Cognitive reflection (CRT)

.07

.22

.02

Critical reading (CROMROSS)

$-.17$

.08

$-.16^{*}$

Text condition

.41

.07

$.43 * * *$

Topic beliefs - artificial sweeteners

.04

.03

.09

Topic beliefs $\mathrm{x}$ Text condition

.08

.03

$.20 * *$

Note . Gender: females $=-1$, males $=1$; text condition: no risk $=-1$, risk $=1$.

$p<.05, * * p<.01, * * * p<.001$ 
Table 4

Results of hierarchical analysis for variables predicting trust in the conclusion from the cell phone text

Variable

$B$

$S E B$

$\beta$

Step 1

Gender

$-.17$

.08

$-.17 *$

Self-reported use of cell phone

$-.15$

.09

$-.13$

Self-reported knowledge - cell phone

$-.01$

.04

$-.03$

Step 2

Gender

$$
-.06
$$

.06

$-.06$

Self-reported use of cell phone

$-.18$

.07

$-.16^{*}$

Self-reported knowledge - cell phone

.03

.03

.05

Cognitive reflection (CRT)

$-.06$

.20

$-.02$

Critical reading (CROMROSS)

$-.2$

.08

$-.19 * *$

Risk/no-risk

.18

.06

$.19 * *$

Topic beliefs - cell phone

$-.01$

.02

$-.03$

Topic beliefs x Risk/no-risk

.19

.02

$.54 * * *$

Note . Gender: females $=-1$, males $=1$; text condition: no risk $=-1$, risk $=1$.

$p<.05, * * p<.01, * * * p<.001$ 


\section{Figure Caption}

Figure 1: Interaction between topic beliefs and text condition for trust in the artificial sweetener conclusion.

Figure 2: Interaction between topic beliefs and text condition for trust in the cell phone conclusion. 


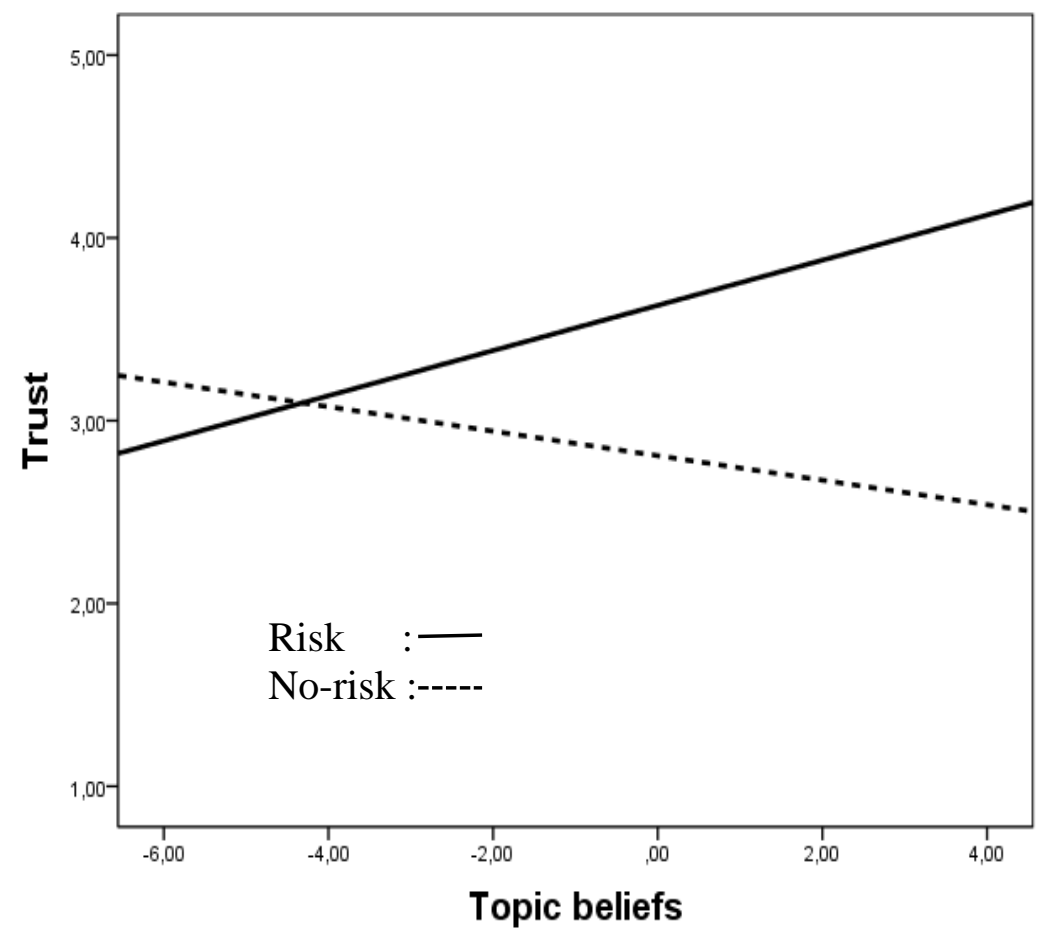

Figure 1

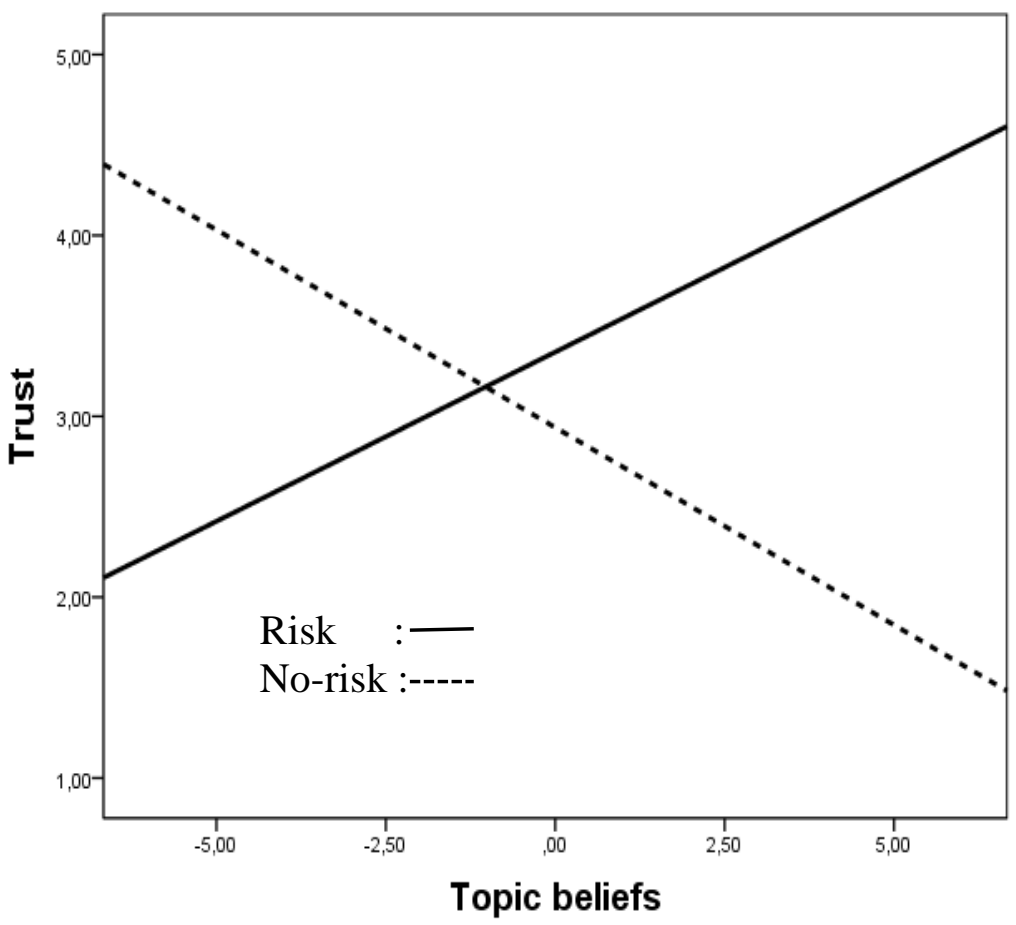

Figure 2 